\title{
The cross-talk between family and pediatrician: The case of bronchial asthma
}

\author{
Salvatore Leonardi, Rossella Pecoraro, Maria Teresa Garozzo, Alfina Coco, Mario La Rosa
}

Department of Pediatrics, Bronchopneumoallergology and Cystic Fibrosis Unit, University of Catania, Catania, Italy;

*Corresponding Author: leonardi@unict.it

Received 27 November 2012; revised 28 December 2012; accepted 4 January 2013

\begin{abstract}
Today the most important challenge facing the pediatrician is the increasing prevalence of chronic diseases. With this regard, pediatricians play a key role in the management of these conditions. The closeness with the family, the knowledge of the clinical case and the care continuity allow the pediatrician to acquire a position of director of every case. When pathological events have a chronic feature, suddenly the quality of life of the whole family changes. For this reason the first communication of chronic disease is very important and the task of the pediatrician should be to provide a positive message to help the family in facing the difficulty of this new challenge. The bronchial asth$\mathrm{ma}$ is the most common chronic disease worldwide. The incidence, the prevalence, and the mortality of the disease have increased in children over the past decades. These trends are particularly marked above all in preschool children. The success reached by Pediatricians is closely related to the compliance and the implementation of the therapy followed by the little patient and his family. With this regard authors, in this review, focus on the illustration of several strategies, based on the pediatrician' skills and medicine documents, that can be used for the improvement of communication among pediatrician-family and child, never forgetting the human aspect of the same doctor, that should conciliate with the scientific knowledge in the taking care of a specific chronic disease.
\end{abstract}

Keywords: Cross-Talk; Bronchial Asthma; Children

\section{THE PAEDIATRICIAN'S ROLE IN CHRONIC CONDITIONS}

Paediatricians are "committed to the attainment of optimal physical, mental, and social health and well-being for all infants, children, adolescents, and young adults", according to the mission statement of the American Academy of Paediatrics (AAP). Despite this, paediatricians are sometimes narrowly viewed as specialists who only provide assessment and treatment of "medical" problems. This view overlooks the strengths and experiences paediatricians have in providing and coordinating services to ease stress and crises in the lives of children, adolescents, and their families. In fact, for a majority of children, paediatric providers are taking responsibility for the management of psychosocial conditions that were historically managed by mental health specialists [1].

Today the most important challenge facing the paediatric providers is the increasing prevalence of chronic diseases. In fact they play a key role in the management of these conditions. Childhood chronic disease involves all family members, particularly parents, who play an important role in the cooperation between patients and health care professionals. Higher level of psychological distress in parents of children with chronic disease has been reported in several studies [2-6]. The closeness with the family, the knowledge of the clinical case and the continuity of the care make the paediatrician the director of every case. The doctor tries to carefully communicate the disease to the family but he doesn't know what are their doubts and concerns.

Parental beliefs shape the context within which children who have asthma receive their care $[7,8]$. Evidence exists that parental beliefs have a developmental progression $[9,10]$ and that they have a direct and indirect influence on the child's beliefs and self-management actions [11]. Particularly when the child is younger than 11 years, parental perceptions provide important information to be considered as providers make decisions [12].

Less is known about the changing nature of specific parental fears and concerns despite our knowledge that specific parental education appears to be more effective than global education in disease management [13]. We also know little about the changing nature of what information parents feel is critical for their providers to 
know about their families' lived experience with asthma in order to best design the child's asthma action plan. One way to obtain this information is through the use of parental focus groups.

The first communication is crucial to give a positive motivation to the family who is facing this new challenge. At this stage it is useful to delivery of specific material for the pathology to the family. This one will help the parents or the little patients to find the answer to unresolved issues.

The concepts needed to understand the implication of chronic disease in childhood are two: the children's understanding of the disease and the consequence of the disease in the different stages of child development. Health professionals who care for children with chronic disease should understand if communications is suitable. In paediatrics the communication process becomes more complex traits: the child is the patient and the parents are the partners. This "paediatrician-child-parent" triangle could create erroneous interpretation and conflicts (Table 1). The paediatrician with knowledge of all health information of the child takes the lead in a process of acceptance of the children's disease and for maintaining a better quality of life.

\section{COMMUNICATION PAEDIATRICIAN-PARENTS IN THE ASTHMATIC DISEASE}

Asthma has become the most common childhood chronic disease in the industrialized world, and it is also increasing in developing regions $[14,15]$. The evolution of asthma to severe and persistent form is growing, and often results in aggravation of underestimated or insufficiently treated mild and moderate form. The OMS considered asthma one of the biggest problems in order of public health and focused the attention on the need to monitor the lung disease most common in the world.

Although there are improvements in the clinical knowledge and in the treatment of the disease, there is a worsening in the epidemiological conditions. There is suggestive evidence for a link between exposure to particle air pollution and the increase of asthma prevalence. It is well confirmed that exposure to passive tobacco smoke in childhood increases the risk of asthma and allergic disease, and a growing database of immuno-toxicological studies indicate that also diesel exhaust particles has a potential to improve the risk of asthma [16-18].

Asthma is a heterogeneous disorder that is characterized by variable airflow obstruction, airway inflammation and hyper-responsiveness, and reversibility either spontaneously or as a result of treatment [19].

The diagnosis of asthma is not easy, especially in children. The symptoms range from minor to severe and vary from person to person. The most common signs of asthma are: coughing, usually at night, during the early hours of the morning and during exercise, wheezing and breathing problems like dyspnea.

Correctly diagnosing asthma is the first step toward attaining disease control. In general, a diagnosis of asthma is established if episodic symptoms of airflow obstruction or airway hyper-responsiveness are present, airflow obstruction is at least partially reversible, and alternative diagnoses are excluded. The guidelines recommend the use of a detailed medical history, the results of a physical examination (focusing on the upper respiratory tract, chest, and skin), and the results of spirometry (for patients aged 5 years or older) in making the diagnosis. Any additional studies necessary for excluding alternative diagnoses or identifying other potential causes of symptoms should also be performed (e.g., chest radiography, specific blood tests) [20].

Asthma is a chronic disease that still must be treated daily with a specific drug therapy for each individual [21]. It is a debilitating disease. When it occurs in childhood it causes a great deterioration in the quality of life. The management of the disease often requires a constant and lasting therapy and communication paediatricianparents is not always satisfactory. In many cases the parents, because of a lack of information, underestimate the disease and 2 of 3 children don't receive an adequate treatment. With this regard, in the "Room to Breath" study, William et al. performed 1294 parental interview worldwide and 943 in their children. The authors found that parents from all country surveyed either underestimate the severity of their children's asthma, or have low health expectations, as a complete asthma control is rare [22].

In case of severe symptoms the effects of asthma on the child's quality of life and social activities of the parents is particularly important. The family feels fair, panic, guilt and frustration. Full attention should be paid to the school age children. Because of illness they could often be absent from school, they could not regularly play sports and they could undergo frequent hospitalisation if not properly treated. Asthmatic children and adolescent can play sports, in fact some Olympic athletes are asthmatic people. With this regard, practicing physical activity and making the correct therapy with salbutamol and leukotriene should treat the exercise-induced asthma.

Chronic asthma could have consequences on the child's cognitive development. The disease could slow the academic learning and the social interaction. Baker et al. exanimated the friendships and social expectations of children with perinatal acquired HIV and compare them to children with moderate to severe persistent asthma and healthy children of HIV-positive mothers. The authors found that children with asthma demonstrated poorer indicators of friendship and the most negative social ex- 
Table 1. The priority triangle in the communication among children-parents-pediatrician.

\begin{tabular}{|c|c|c|}
\hline Pediatrician aims & Parents' unresolved questions & Child's exigences \\
\hline $\begin{array}{l}\text { Identification of the stage of the } \\
\text { disease }\end{array}$ & Therapy during the episode of acute asthma & I want to run and play with other children \\
\hline $\begin{array}{l}\text { Analysis on how the family knows } \\
\text { the disease }\end{array}$ & $\begin{array}{c}\text { Doubts on correlation between physical exercise } \\
\text { and asthma }\end{array}$ & I want to go with my class-mates in the countryside \\
\hline $\begin{array}{l}\text { Identification of the chronic feature } \\
\text { of the disease }\end{array}$ & hereditary of asthma & I would like to have a dog \\
\hline $\begin{array}{l}\text { Identification of the healthy status of } \\
\text { the patient }\end{array}$ & doubts on the chronic feature of the therapy & I want to go swimming \\
\hline Decision of an adequate therapy & collateral effects of the long-term therapy & $\begin{array}{l}\text { I have an important basket/football competition, how } \\
\text { to afford it }\end{array}$ \\
\hline $\begin{array}{c}\text { Analysis of the efficacy of the } \\
\text { treatment }\end{array}$ & compliance to the therapy in preschool children & $\begin{array}{l}\text { I do not want to perform a venous withdraw when I } \\
\text { go to the Pediatrician }\end{array}$ \\
\hline Symptoms control & Virus-triggered episodes of asthma & Mom, when I run I cough, what should I do? \\
\hline Control of the disease & Asthmatic children and animals & \\
\hline \multirow[t]{2}{*}{ Improving the quality of life } & Asthmatic children and spring season & \\
\hline & $\begin{array}{l}\text { The role of a sea travel in the improvement of } \\
\text { asthmatic symptoms }\end{array}$ & \\
\hline
\end{tabular}

pectations of the three groups [23].

At school, the lack of trained staff to deal with the disease causes many absences of the child and forces parents to miss work days. In addition, parents (especially the mother) are often forced to leave the workplace to assist the child in case of asthma attacks during school hours. All this leads to serious psychological distress and economic loss aggravated by expensive management of the disease. Hence the need for appropriate education of the family for self-care.

The role of the paediatrician is to treat the disease and to take care of the patient. He should help the family to raise self-esteem and autonomy in the management of the disease. Parents should have to take conscience of the disease and help the child to accept it.

In recent years there is a general unwillingness in the acceptance of the pathology and a general contestation against the therapy. Koster et al. observed 170 children who used inhaled corticosteroids for the management of asthma. They found that 76 (45\%) children had uncontrolled asthma. Low maternal education (RR 1.6, 95\% CI: 1.0 - 2.4) was associated with uncontrolled asthma. Parental necessity beliefs about medication use to maintain present and future health and parental concerns about potential adverse consequences of medication were also associated with uncontrolled asthma (RR 1.6, 95\% CI: 1.1 - 2.2; and 1.6, 95\% CI: 1.0 - 2.5, respectively) [24].

The success of therapeutic intervention is closely related to the family and child compliance. The role of the paediatrician is to explain the value of therapy to achieve adequate compliance.

The family should be educated to recognize early bronchial obstructive symptoms as cough and dyspnoea.
The correct recognition of symptoms is useful to avoid excessive worries and unreasonable treatment. For example, the inhalation therapy is the most important for the treatment of bronchial asthma even if it is considered as palliative [25]. Moreover, asthma attacks are frequently treated with cycle of steroids by inhaled way for short time (about 2 weeks), and then suspended without the adequate time to reaction against the inflammatory process, that is the important element of the pathogenesis of the disease [26-28]. In fact for an adequate response to the therapy, inhaled steroids should be continuously administered at least for 2 - 3 months.

Another problem to afford with asthmatic patients with recent diagnosis is the way to educate the family to the correct use of the spacer and nebulizer for the inhaled therapy and the use of a mouthpiece rather than the mask in the aerosol therapy, in fact the effect of the medicine depends on the way it is performed [29].

It is, moreover, important to explain that the effectiveness of the treatment depends on the constancy of the treatment self, in order to reduce the frequency and the severity of acute episodes, instead of treat them during the inflammatory process [30].

It is fundamental to explain the role and the differences among medicines used during an acute episode: generally short acting bronchodilators associated with inhaled cortisone are sufficient for a good control of the acute episode. Instead, as far as the basic therapy of the disease, anti-leukotrienes, inhaled steroids, long acting $\beta$-2 agonists and immunotherapy can achieve a good control in a chronic condition [31-34].

It is important the education of patient and his family after the prescription of Specific Immunotherapy (SIT). 
A correct knowledge helps to reduce the number of patients that interrupt the therapy before the end, also for its long-efficiency with slow improvements. An adequate paediatrician-family communication could improve the compliance to chronic therapies such as SIT [35].

\section{TRAINING PROGRAM FOR THE FAMILIES OF CHILDREN AFFECTED BY ASTHMA}

The first point of the training program to the family focuses on the deep knowledge of the paediatrician of the chronic disease.

The knowledge of specialists, such as pediatricians, is based on three criteria:

- knowledge of the pathogenesis;

- treatment of risks and benefits;

- knowledge of the specific case, as paediatricians act because they know children and their family.

The paediatrician communication skills have a very important role for the family arousing requests. Picking up the knowledge of parents with scientific material, the communication between paediatrician and parents become a formative and educational event. The useful tools that the paediatrician could use in this sense are:

- The language: it is the best way to get a good communication in order to be effective and clear the communication has to go with good mime, gestures and voice tone.

- The telephone: even if it is a weak system to communicate, it is usually used to ask brief consultations. So a good phone call has to be exhaustive and convinceing to the parents' requests.

- Educational boards: are supports to the direct interview, available to parents. They are useful because the information that parents record during the interview is reduced on about $10 \%$ - $20 \%$, especially if there are children crying or who needs attentions.

The educational schedules are based on the following criteria: the information has to be demonstrated by scientific discoveries to greater veracity; the schedule should be clear and understandable; the schedule has to be delivered in an appropriate moment; it must be updated at least every two years; the language should considered the specific user.

- Textbooks: they could be created as a library in paediatric ambulatories or a list of useful books clearly understandable, that parents could read to deepen doubts about their children. The paediatrician must ensure the reliability of these books. Also the books are good instruments to education: different projects are intended to encourage reading from the earliest years of life to improve the communication between parents, children and family doctor.

- Posters: are a classic way to explain a message easy to read, reduced to the essential.

- Multimedia material: it is important to have the possibility to use video-recorders, CD, Internet to health education. Nowadays there are different websites that explain health education to parents. The role of the paediatrician is to give more information about them [26].

We have above described the strategies to improve the education of families on their children health and diseases, nevertheless it is relevant to focus also on the skills of paediatricians used for a better comprehension of the exigencies of the families and their children. With this regard, the fundamental skills for a good communicator are:

- Attention and listening: to focus the difference on the aspects of the pathology that are interesting to the paediatrician or to parents. The doctor aim is the patients care, in fact children want to do sport and play with friends while parents don't often allow them to practice physical activity for their fear of the disease self, even if at the basis there is a lack of knowledge of the pathogenesis of the disease.

- Consistency of information: it is important to have a good compliance to the treatment. The compliance is reduced when the information is given by different professionals (paediatrician, specialist, hospital doctor) or when there is not a clear and univocal consensus on the disease. Mass media have an important role because "parents' library" is based on Internet navigation, with wrong interpretation of information, following wrong recommendations.

- Research commitment and adherence by the family: when events, conflicts, difficulties in communication could lead to failure of the prevention and therapy, the communication between parents and paediatrician has to be reinforced.

- Education: the education in medical field is defined as: "planned process of learning the information and behaviour that help to give decisions about health problems". Even if paediatrician's information is correct the decision about the health of child is on parent's responsibility. For this reason it is important to aware the family of their choice and related consequences $[28,36,37]$.

- Concordance of the treatment plan: considering the child's needs, the severity and the variability of the course of his disease.

- Verification and monitoring: the compliance to the treatment is accurate during the acute event, but there is a progressive decrease in the subsequent months. Therefore a follow up could help parents and their children to find an adequate therapy plan for the single patient in that specific moment.

- Humanization of the structures: as the asthma is a 
disease with chronic course tending to distort life of child and his family, information, explanations and messages about the disease should be given in a hospitable and reassuring environment.

\section{CONCLUSIONS}

It is possible to affirm that health education is an essential element to the communication process between paediatrician and family, inside the trust relationship between them. This communication is very important above all when the little patient is affected by chronic diseases, such as asthma, for a better compliance to the treatment of the disease and its control.

There are several strategies based on the paediatrician skills and medicine documents that can be used for the improvement of communication among paediatricianfamily and child, never forgetting the human aspect of the same doctor, that should conciliate with the scientific knowledge and process to take care of a specific chronic disease.

\section{REFERENCES}

[1] Ringel, J.S. and Sturm, R. (2001) National estimates of mental health utilization and expenditures for children in 1998. Journal of Behavioral Health Services \& Research, 28, 319-333. doi:10.1007/BF02287247

[2] Hyland, M.E., Finnis, S. and Irvine, S.H. (1991) A scale for assessing quality of life in adult asthma sufferers. Journal of Psychosomatic Research, 35, 99-110. doi:10.1016/0022-3999(91)90011-C

[3] Juniper, E.F. (1997) How Important is the quality of Life in Pediatric Asthma? Pediatric Pulmonology, 15, 17-21.

[4] Juniper, E.F., Wisniewski, M.E., Cox, F.M., Emmet, A.H., Nielsen, K.E. and O’Byrne, P.M. (2004) Relationship between quality of life and measures of clinical status in asthma: A factor analysis. European Respiratory Journal, 23, 287-291. doi:10.1183/09031936.04.00064204

[5] Faulkner, M.S. and Clark, F.S. (1998) Quality of life for parents of children and adolescents with type 1 diabetes. The Diabetes Educator, 24, 721-727. doi:10.1177/014572179802400607

[6] Miraglia del Giudice, M., Marseglia, A., Leonardi, S., La Rosa, M., Salpietro, C., Arrigo, T.,Brunese, F.P., Arrigo, T. and Perrone, L.(2011) Allergic rhinitis and quality of life in children. International Journal of Immunopathology and Pharmacology, 24, 25-28.

[7] Bender, B., Milgrom, H., Rand, C. and Ackerson, L. (1998) Psychological factors associated withmedication nonadherence in asthmatic children. Journal of Asthma, 35, 347-353. doi:10.3109/02770909809075667

[8] Wallerstedt, D.B. and Bellanti, J.A. (1998) The emotional needs of allergic and asthmatic patients and their families. Allergy \& Asthma Proceedings, 19, 189-191. doi:10.2500/108854198778557845

[9] Horner, S.D. (1997) Uncertainty in mothers' care of their ill children. Journal of Advanced Nursing, 25, 658-663. doi:10.1046/j.1365-2648.1997.00232.x

[10] Horner, S.D. (1998) Catching the asthma: Family care for school-aged children with asthma. Journal of Pediatric Nursing, 13, 356-366. doi:10.1016/S0882-5963(98)80024-9

[11] Kieckhefer, G. (1987) Testing self-perception of health theory to predict health promotion and illness management behaviour in children with asthma. Journal of Pediatric Nursing, 2, 381-391.

[12] Guyatt, G.H., Juniper, E.F., Griffith, L.E., Feeny, D.H. and Ferrie, P.J. (1997) Children and adult perceptions of childhood asthma. Pediatrics, 99, 165-168. doi:10.1542/peds.99.2.165

[13] Clarck, C.J. (1994) The influence of education on morbidity and mortality in asthma (including the use of open access hospital admission for severe attacks). Monaldi Archives for Chest Disease, 49, 169-172.

[14] Heinrich, J. (2011) Influence of indoor factors in dwellings of the development of childhood asthma. International Journal of Hygiene and Environmental Health, 214, 1-25. doi:10.1016/j.ijheh.2010.08.009

[15] Leonardi, S., Miraglia del Giudice, M., La Rosa, M. and Bellanti, J.A. (2007) Atopicdisease, immune system, and the environment. Allergy \& Asthma Proceedings, 28, 410 417. doi:10.2500/aap.2007.28.2954

[16] Rigoli, L., Briuglia, S., Caimmi, S., Ferrau', V., Gallizzi, R., Leonardi, S., La Rosa, M., Salpietro, C.(2011) Geneenvironment interactions in childhood asthma. International Journal of Immunopathology and Pharmacology, 24, 41-47.

[17] McConnell, R., Berhane, K., Gilliland, F., London, S.J., Vora, H., Avol, E., Gauderman, W.J., Margolis, H.G., Lurmann, F., Thomas, D.C. and Peters, J.M. (1999) Air pollution and bronchitic symptoms in southern California children with asthma. Environmental Health Perspectives, 107, 1-9. doi:10.1289/ehp.99107757

[18] Hajat, S., Haines, A., Goubet, S.A., Atkinson, R.W. and Anderson, H.R. (1999) Association of air pollution with daily GP consultations for asthma and other lower respiratory conditions in London. Thorax, 54, 597-605. doi:10.1136/thx.54.7.597

[19] Ciprandi, G., Salpietro, A., Leonardi, S., Tosca, M.A., Miraglia del Giudice, M., Salpietro, C., La Rosa, M., Cirillo, I., Signori, A. and Marseglia GL. (2012) Impaired spirometry may suggest sensitization. Journal of Biological Regulators \& Homeostatic Agents, 26, 15-18.

[20] Lemanske Jr., R.F. and Busse, W.W. (2010) Asthma: Clinical expression and molecular mechanisms. Journal of Allergy and Clinical Immunology, 125, 95-102. doi:10.1016/j.jaci.2009.10.047

[21] Pedersen, S.E., Hurd, S.S., Lemanske, R.F.Jr, Becker, A., Zar, H.J., Sly, P.D., Soto-Quiroz, M., Wong, G. and Bateman, E.D. (2011) Global strategy for the diagnosis and management of asthma in children 5 years and younger. Pediatric Pulmonology, 46, 1-17. doi:10.1002/ppul.21321

[22] Wechsler, M.E. (2009) Managing asthma in primary care: 
Putting new guideline recommendation into context. Mayo Clinic Proceedings, 84, 707-717. doi:10.4065/84.8.707

[23] Baker, S.E., Niec, L.N. and Meade, J. (2012) A comparison of friendship quality and social functioning among children with perinatally acquired HIV, children with persistent asthma, and healthy children of HIV-positive mothers. Journal of Pediatric Psychology, 37, 580-590. doi:10.1093/jpepsy/jss007

[24] Koster, E.N., Wijga, A.H., Koppelman, G.H., Postma, D.S., Brunekreef, B., De Jongste, J.C., Smit, H.A., Hoekstra, M.O., Raaijmakers, J.A. and Maitland-van der Zee, A.H. (2011) Uncontrolled asthma at age 8: The importance of parental perception towards medication. Pediatric Allergy and Immunology, 22, 462-468. doi:10.1111/j.1399-3038.2011.01150.x

[25] Lo Valvo, L., Leonardi, S., Marseglia, G.L., Miraglia Del Giudice, M., Salpietro, C., Ciprandi, G. and La Rosa, M. (2011) Inhalationtherapy in asthmastic and notasthmaticchildren. International Journal of Immunopathology and Pharmacology, 24, 61-67.

[26] Carroll, W.D., Wildhaber, J. and Brand, P.L. (2010) Sad, sedentary, and on the sidelines: The impact of asthma on the lives of Canadian children compared with global reports in the room to breathe survey. Chest, 138, 756. doi:10.1378/chest.10064

[27] Radzik, D., Peroni, D.G., Pescollderungg, L., Piacentini, G.L., Chatzimichail, A. and Boner, A.L. (2005) Nebulizers or pressurized metered- dose inhalers in the treatment of asthma exacerbations. Allergy \& Asthma Proceedings, 26, 207-209.

[28] Preventive Services Task Force (1996) Guide to clinical preventive services. 2nd Edition, William and Wilkins, Baltimora.

[29] Joels, C. (2012) Protocol for assessing inhaler technique in patients with asthma. Nursing Standard, 26, 43-47.

[30] Del Giudice, M.M., Pedullà, M., Brunese, F.P., Capristo, A.F., Capristo, C., Tosca, M.A., Leonardi, S. and Cip- randi G. (2010) Neutrophiliccells in sputum of allergicasthamaticchildren. European Journal of Inflammation, 8, 151-156.

[31] Herzog, R. and Cunningham-Rundles, S. (2011) Pediatric asthma: Natural history, assessment, and treatment. Mount Sinai Journal of Medicine, 78, 645-660. doi:10.1002/msj.20285

[32] Vitaliti, G., Leonardi, S., Miraglia del Giudice, M., Salpietro, A., Artusio, L., Caimmi, D., Arrigo, T., Salpietro, C., Ciprandi, G. and La rosa, M. (2012) Mucosalimmunity and sublingualimmunotherapy in respiratorydisorders. Journal of Biological Regulators \& Homeostatic Agents, 26, 85-94.

[33] Wasilevich, E.A., Clark, S.J., Cohn, L.M. and Dombkowski, K.J. (2011) Long-acting $\beta$-agonist monotherapy among children and adults with asthma. American Journal of Managed Care, 17, 91-95.

[34] Miraglia del Giudice, M., Marseglia, G.L., Leonardi, S., Tosca, M.A., Marseglia, A., Perrone, L. and Ciprandi, G. (2011) Fractionalexhalednitricoxidemeasurements in rhinitis and asthma in children. International Journal of Immunopathology and Pharmacology, 24, 29-32.

[35] La Rosa, M., Lionetti, E., Leonardi, S., Salpietro, A., Bianchi, L., Salpietro, C., Miraglia Del Giudice, M., Ciprandi, G. and Marseglia, G.L. (2011) Specific immunotherapy in children: The evidence. International Journal of Immunopathology and Pharmacology, 24, 6978.

[36] Welsh, E.J., Hasan, M. and Li, P. (2011) Home-based educational interventions for children with asthma. $\mathrm{Co}$ chrane Database of Systematic Reviews, 5, Article ID: CD008469

[37] Zahradnik, A. (2011) Asthma education information source preferences and their relationship to asthma knowledge. Journal of Health and Human Services Administration, 34, 325-351. 